\title{
CDC's Prevention Research Centers Program: Translating Research into Action with Communities
}

\author{
Alice Ammerman • Jeffrey R. Harris • \\ Ross C. Brownson · Jose Antonio Tovar-Aguilar
}

Published online: 25 August 2011

(C) Springer Science+Business Media, LLC 2011

Chronic diseases account for more than $75 \%$ of the nation's health care costs, and much of that cost is preventable (Remington, Brownson, \& Wegner, 2010). Primary prevention of chronic disease requires transdisciplinary skills and collaborations to generate a strong evidence base to guide implementation and

This editorial was written on behalf of the PRC Steering Committee.

Individuals and organizations seeking assistance from or collaboration with a PRC can identify one from the CDC website: http://www.cdc.gov/prc/.

A. Ammerman $(\bowtie)$

Center for Health Promotion and Disease Prevention (a PRC), University of North Carolina at Chapel Hill, Chapel Hill, NC, USA

e-mail: alice_ammerman@unc.edu

A. Ammerman

Gillings School of Global Public Health, Chapel Hill, NC, USA

\section{J. R. Harris}

Health Promotion Research Center, School of Public Health, University of Washington, Seattle, WA, USA e-mail: jh7@u.washington.edu

\section{R. C. Brownson $(\bowtie)$}

Prevention Research Center in St. Louis, George Warren Brown School of Social Work, Washington University in St. Louis, 660 S. Euclid, Campus Box 8109, St. Louis, MO 63110, USA

e-mail: rbrownson@wustl.edu dissemination of programs, policies, and systemslevel change. A focus on the most efficient and costeffective approaches is critical for sustainable change. Prevention Research Centers (PRCs) take this approach. The 37 PRCs, funded by the Centers for Disease Control and Prevention (CDC), are a network of academic, community, and public health partners (health care institutions, businesses, public health agencies, and community organizations) committed to conducting research that benefits the research participants and the communities in which they live.

\section{R. C. Brownson \\ Division of Public Health Sciences, Department of Surgery, Washington University School of Medicine, St. Louis, MO, USA}
J. A. Tovar-Aguilar
National Community Committee, Partnership for Citrus Workers Health, Florida Prevention Research Center, Farmworker Association of Florida, Apopka, FL, USA e-mail: tonytovar@hotmail.com 
Prevention research funding provided by state and federal governments is leveraged by PRCs to bring millions of dollars into state economies, providing jobs and important services to community members as a part of the research process. A unique feature of the PRCs' core funding is that, unlike most other research funding, it provides essential infrastructure to support the translation of research to practice through community partners, thus ensuring greater impact and efficiency of research dollars. Using this core support, PRCs are also successful at leveraging additional research and program funding from the National Institutes of Health (NIH); foundations; and other federal, state, and local sources. On average, for every $\$ 1$ received from the CDC program in 2010 core funds, the 32 Comprehensive PRCs generated an additional $\$ 5.42$ in funding. Research dollars invested in PRCs result in direct community benefits that can be sustained over time rather than end with the grant cycle. The applied public health research described below exemplifies the crucial work conducted by the PRCs.

\section{Core Activities of the PRCs}

Identifying the Most Critical Health Issues in Communities

Critical health issues are defined both by epidemiologic data and by the concerns of local community members (Fielding \& Frieden, 2004). PRCs have access to the most extensive and up-to-date health indicator data and related behavioral risk factors. Each PRC also includes a community advisory committee charged with assuring that health priorities of local citizens and organizations are addressed. By integrating these sources of information, PRCs ensure that prevention efforts target areas of greatest potential impact given that there is both the need and the will to address them.

\section{Mobilizing Experienced Multidisciplinary Teams to Address Health Concerns}

Addressing complex health problems requires knowledge of the current science base as well as an understanding of associated political, economic, and sociocultural factors. Academic-community partnerships fostered by PRCs strike this balance. PRCs bring together faculty who come from across traditional academic silos and are committed to community-engaged research. Complementing these efforts, community advisory committees in the PRCs are experts in understanding the complexity of selecting and implementing the most appropriate prevention approaches in a particular setting and in ensuring there is adequate community support for long-term sustainability. PRC research networks engage multiple PRC sites on topics such as cancer, epilepsy, healthy aging, physical activity policy, and nutrition/obesity policy to further facilitate multidisciplinary exchange and ensure that interventions are relevant to all regions of the country. These research networks have also provided meaningful links across federal agencies; the PRC collaboration with the NIH Women's Health Initiative, for example, contributed to an array of new scientific findings (Riley \& Finnegan, 1997).

\section{Designing Innovative Solutions}

The literature on "wicked problems" (the most intractable/difficult-to-solve societal problems) suggests that innovation and high impact are most likely to occur when those involved are pushed to seek solutions beyond their usual disciplinary boundaries (Kreuter, De Rosa, Howze, \& Baldwin, 2004). PRCs represent a rare blend of diverse academic disciplines and community partners collaborating to maximize this potential for innovation and impact. For example, parks and recreation staff may not have thought to engage the department of transportation in designing strategies to increase physical activity among youth, and academic nutritionists may be pushed by community partners to understand the behavioral and social-capital benefits of community gardens rather than just the vitamin and mineral content of seasonal foods.

Implementing the Most Feasible Evidence-Based Interventions to Achieve High Impact

PRCs conduct original research to test innovative solutions, and they conduct program and policy evaluation to determine the impact of existing interventions. Both kinds of research are essential to ensuring that primary prevention interventions can be 
effectively implemented in a wide variety of settings. Also, collaboration with community partners ensures that original research is addressing areas of greatest need, and evaluation is grounded in the context of "real-world" program implementation. Several PRC products provide ongoing access to all of the resources necessary to identify and implement evidence-based obesity interventions (e.g., Center for Training and Research Translation, http://www. center-trt.org/; Leeman, Sommers, Leung, \& Ammerman, 2011) while identifying key gaps in the literature requiring further research (Brennan, Castro, Brownson, Claus, \& Orleans, 2010). An American Lung Association and PRC collaboration aids in the dissemination and adoption of Not On Tobacco, one PRC's teen smoking cessation program (http://www. notontobacco.com/).

\section{Building the Science of Dissemination Research}

Dissemination research and implementation science is a relatively new field (Kerner, Rimer, \& Emmons, 2005), and PRCs have contributed substantially to it. Interventions developed, tested, and evaluated by PRCs are designed for dissemination, in part by engaging community partners in all stages of the research process. In addition, PRC programs and policies are designed to work in resource-challenged communities and thus reach populations with the greatest need. Not only do PRCs disseminate effective interventions, they study the process of dissemination to identify cost-effective approaches with the greatest reach. For example, a middle school curriculum that resulted in a reduction in TV viewing time and obesity has been distributed to 48 states and 20 countries (Franks et al. 2007); a physical activity program for older adults that helps keep them active, independent, and in their own homes rather than in expensive nursing homes is now in 486 locations across the country, reaching 14,000 adults nationwide (Belza, Snyder, Thompson, \& LoGerfo, 2010); and a smoking cessation program that decreased teen smoking has now reached more than 100,000 teens in 48 states (Anesetti-Rothermel, Noerachmanto, Horn, \& Dino, 2011). PRC research is among the interventions included in a number of systematic reviews, including the CDC's Community Guide (Zaza, Briss, \& Harris, 2005). To disseminate the findings of this work, PRCs published approximately
400 journal articles in the peer-reviewed scientific literature in 2010 alone.

Training Practitioners to Enhance

Evidence-Based Practice

The formal training of persons working in public health is much more variable than that in medicine or other clinical disciplines (Tilson \& Gebbie, 2004). Fewer than half of public health workers have any formal training in a public health discipline such as epidemiology or health education (Turnock, 2009). Among the practitioner-focused PRC training programs are those focusing on evidence-based public health, physical activity and public health for practitioners, and social marketing (Franks et al., 2005). These programs have been evaluated and show important impacts to workforce capacity in public health practice.

\section{The Bottom Line}

The PRC network is a highly productive extramural research program that has served CDC well for more than 25 years. PRCs develop, test, and disseminate prevention practices and policies that save lives, preserve livelihoods, and conserve health care dollars. The work of the PRCs reaches nearly 30 million Americans in 103 partner communities, including underserved populations that suffer an excess burden of disease and disability. The backbone of any effort to improve population health and reduce health care costs is research on disease etiology, public health surveillance to assess burden, evaluation of intervention programs and policies, and "scaling-up" effective intervention strategies. Through scientific rigor, collaborative community partnerships, and practical application, the PRCs work on a daily basis to find new ways to achieve these goals and improve the nation's quality of life. Not only do the PRCs promote the health and well-being of our citizens, keeping them at work and able to care for their families, but they also generate employment opportunities through universities and communities. The work of PRCs addresses solutions to multiple chronic diseases and tackles our nation's most critical health priorities that, if left unaddressed, will cost our society dearly in both lives and dollars. 


\section{References}

Anesetti-Rothermel, A., Noerachmanto, N., Horn, K. A., \& Dino, G. A. (2011). Beyond reach and effectiveness: Evaluating the Not-On-Tobacco (N-O-T) program in West Virginia from 2000 to 2005. Health Promotion Practice. Advance online publication. doi:10.1177/ 1524839910386183.

Belza, B., Snyder, S., Thompson, M., \& LoGerfo, J. (2010). From research to practice: Enhance fitness, an innovative community-based senior exercise program. Topics in Geriatric Rehabilitation, 26(4), 299-309.

Brennan, L., Castro, S., Brownson, R., Claus, J., \& Orleans, T. (2010). Accelerating evidence reviews and broadening evidence standards to identify effective, promising, and emerging policy and environmental strategies for prevention of childhood obesity. Annual Review of Public Health, 32, 199-223. doi:10.1146/annurev-publhealth031210-101206.

Fielding, J. E., \& Frieden, T. R. (2004). Local knowledge to enable local action. American Journal of Preventive Medicine, 27(2), 183-184.

Franks, A. L., Brownson, R. C., Bryant, C., Brown, K. M., Hooker, S. P., Pluto, D. M., et al. (2005). Prevention Research Centers: Contributions to updating the public health workforce through training. Preventing Chronic Disease: Public Health Research, Practice, and Policy, 2(2), A26.

Franks, A. L., Kelder, S. H., Dino, G. A., Horn, K. A., Gortmaker, S. L., Wiecha, J. L., et al. (2007). School-based programs: Lessons learned from CATCH, Planet Health, and Not-On-Tobacco. Preventing Chronic Disease: Public Health Research, Practice, and Policy, 4(2), A33.

Kerner, J., Rimer, B., \& Emmons, K. (2005). Introduction to the special section on dissemination: Dissemination research and research dissemination: How can we close the gap? Health Psychology, 24(5), 443-446.

Kreuter, M. W., De Rosa, C., Howze, E. H., \& Baldwin, G. T. (2004). Understanding wicked problems: A key to advancing environmental health promotion. Health Education \& Behavior, 31(4), 441-454.

Leeman, J., Sommers, J., Leung, M. M., \& Ammerman, A. (2011). Disseminating evidence from research and practice: A model for selecting evidence to guide obesity prevention. Journal of Public Health Management and Practice, 17(2), 133-140.

Remington, P., Brownson, R., \& Wegner, M. (Eds.). (2010). Chronic disease epidemiology and control (3rd ed.). Washington, DC: American Public Health Association.

Riley, P. L., \& Finnegan, L. P. (1997). Observations from the CDC. The Prevention Research Centers Program: Collaboration in women's health. Journal of Women's Health, 6(3), 281-283.

Tilson, H., \& Gebbie, K. M. (2004). The public health workforce. Annual Review of Public Health, 25, 341-356.

Turnock, B. J. (2009). Public health: What it is and how it works (4th ed.). Sudbury, MA: Jones and Bartlett.

Zaza, S., Briss, P. A., \& Harris, K. W. (Eds.). (2005). The guide to community preventive services: What works to promote health?. New York, NY: Oxford University Press. 